\title{
PACIENTE COM SÍNDROME MIELOPROLIFERATIVA E ALTERAÇÃO UNGUEAL
}

Caso Clínico: Uma mulher, de 66 anos de idade, está em acompanhamento no Serviço de Hematologia do Hospital de Clínicas da UFPR há 9 meses por síndrome mieloproliferativa. Realizou sessões de quimioterapia por dois meses, que foram posteriormente suspensas por toxicidade hematológica. Foi internada na enfermaria de Clínica Médica deste hospital por astenia e náuseas. $\mathrm{Na}$ admissão, apresentava hepatomegalia e esplenomegalia; hemograma que demonstrava hemoglobina de $4,1 \mathrm{~g} / \mathrm{dl}$, leucócitos de 11.170 por $\mathrm{mm} 3$ e plaquetas de 101.000 por mm3; bilirrubinas totais de $2,64 \mathrm{mg} / \mathrm{dl}$, com fração indireta de 1,74 mg/dl; albumina de $3,1 \mathrm{~g} / \mathrm{dl}$ e $\mathrm{LDH}$ de $1645 \mathrm{U} / \mathrm{l}$. Abaixo a imagem das unhas da paciente.

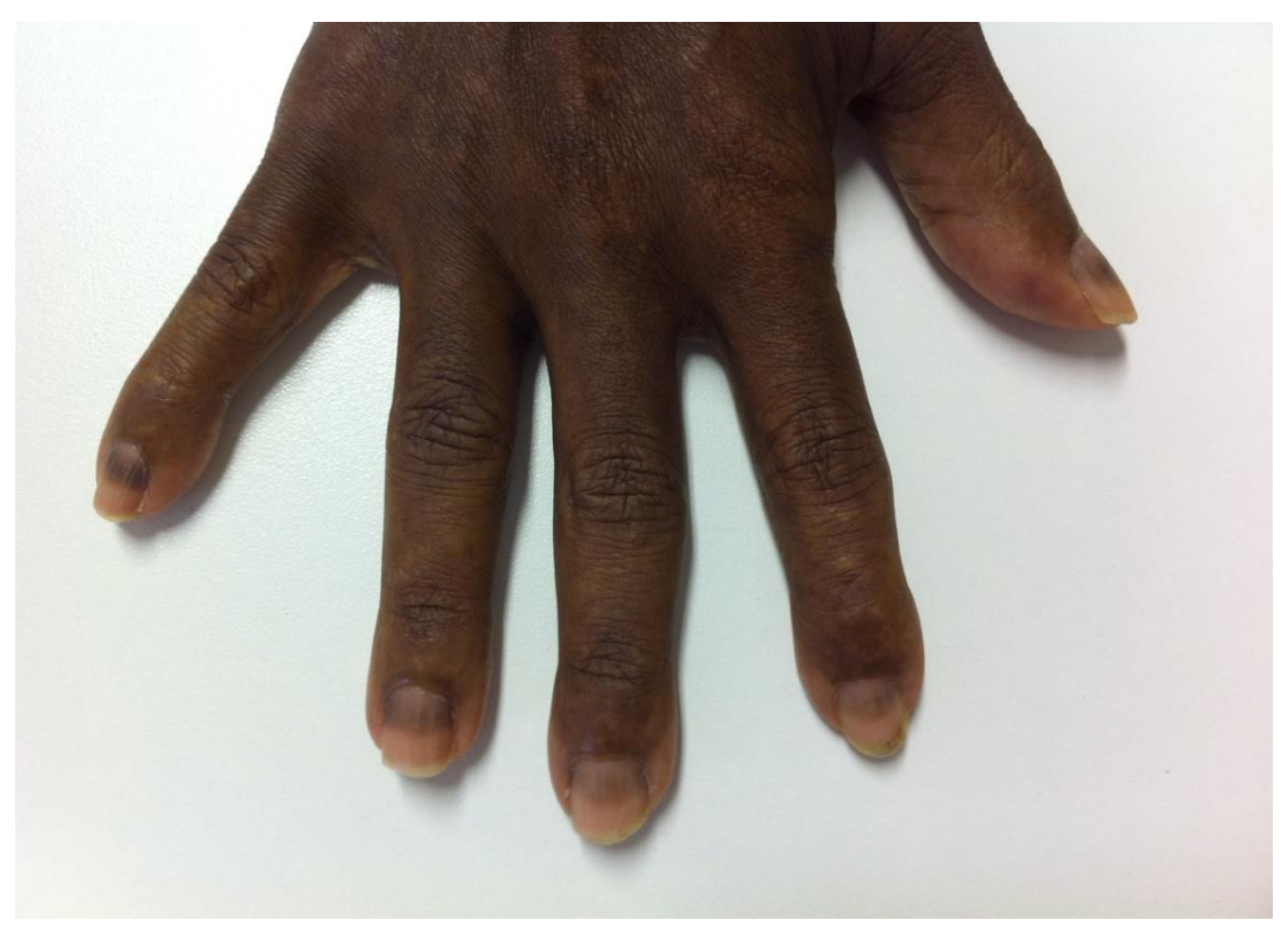

Qual é a alteração ungueal notada neste caso clínico?
A. Melanoníquia longitudinal
B. Unhas de Terry
C. Unhas meio a meio (Unhas de Lindsay)
D. Leuconíquia estriada
E. Linhas de Beau 
REVISTA MÉDICA DA UFPR 


\section{RESPOSTA: A - MELANONÍQUIA LONGITUDINAL}

A melanoníquia longitudinal ou estriada (ML) é uma alteração da cor da unha, que varia do castanho ao negro. A forma localizada, geralmente vista em apenas algumas unhas, geralmente nas mãos, compromete a lâmina ungueal, da borda proximal para a distal. Pode ser induzida por quimioterapia e é habitualmente reversível com o término do tratamento. Os quimioterápicos mais frequentemente associados são a ciclofosfamida, doxorubicina e hidroxiureia. Esta última, que a paciente fazia uso, também se associa a outras complicações mucocutâneas, como xerose, hiperpigmentação da pele e outras alterações ungueais, como onicólise e lúnula azulada.

As unhas de Terry apresentam leito ungueal proximal branco, com faixa eritematosa, de 1 a $2 \mathrm{~mm}$, rosa ou avermelhada distal, descrita em pacientes com cirrose hepática. Unhas de Lindsay, ou unhas meio-a-meio, têm coloração habitual na sua metade distal e cor branca na metade proximal e estão associadas à doença renal crônica. Linhas estreitas, brancas transversais caracterizam a leuconíquia estriada (de Muehrcke), vista na hipoalbuminemia (geralmente inferior a $<2,2 \mathrm{~g} / \mathrm{dl}$ ). As linhas de Beau são depressões transversais do leito ungueal, observadas em infecções graves, IAM, hipotensão ou choque, desnutrição e com alguns quimioterápicos.

\section{REFERÊNCIAS BIBLIOGRÁFICAS}

1. de Franca, E.R.; Teixeira, M.A.G.; Matias, K.F. et al. Efeitos colaterais cutâneos após uso prolongado de hidroxiuréia na Policitemia Vera. An. Bras. Dermatol. 2011, vol.86, n.4, pp. 751-754.

2. The Hand in Diagnosis - Stanford Medicine 25 - Stanford University School of Medicine. In: http://stanfordmedicine25.stanford.edu/the25/hand.html 